\title{
Dependency of Polyelectrolyte Complex Stoichiometry on the Order of Addition. 2. Aluminum Chloride and Poly-vinylsulfate
}

Junhua Chen, Martin A. Hubbe, ${ }^{*}$ John A. Heitmann, Dimitris S.

Argyropoulos, and Orlando J. Rojas

Department of Wood and Paper Science, North Carolina State University, P. O. Box 8005, Raleigh, NC 27695-8005, USA

* Corresponding author. Tel.: +1-919-513-3022; fax: +1-919-515-6302. E-mail address: $m$ hubbe@ncsu.edu (M.A. Hubbe).

\section{Abstract}

In the first part of this series it was shown that the stoichiometry of complexation between oppositely charged polyelectrolytes became increasingly dependent on the order of addition as the concentrations of monovalent and divalent ions were increased. This study considers the effect of aluminum ions on titrations between solutions of a strong poly-acid and a strong poly-base. In addition, the titratable charge of aluminum ion itself was also investigated. It was found that aluminum ions can interfere with the results of charge titrations, and stoichiometric relationships fail to explain the observed results. The word "interfere" implies an unpredictable effect on titration results. Several factors affect this interference. However, by controlling solution $\mathrm{pH}$ and degree of charge neutralization of aluminum ions, the titratable charge of the system can be estimated by streaming current titration. The results are consistent with the presence of aluminum polynuclear species within the ranges of aluminum and base addition where the highest titratable charge was reached. 


\section{Keywords: ELECTROKINETICS, STREAMING CURRENT, ALUMINUM, POLYELECTROLYTE COMPLEXATION, TITRATIONS, STOICHIOMETRY, ORDER OF ADDITION}

\section{Introduction}

In the first part of this series [1] it was shown that endpoints of titrations between a strong poly-acid and poly-base, when detected by the streaming current method, depended on the order of addition. It was observed that this dependency became more pronounced with increasing 1:1 or 1:2 electrolyte concentration. The present investigation involves similar systems except for the use of aluminum chloride instead of simpler salts.

Interactions between aluminum ions and polyelectrolytes play major roles in such applications as water and wastewater treatment [2-4], and papermaking [5-8]. In these applications the streaming current method has emerged as a useful tool to monitor complexation and neutralization phenomena during process optimization [9-10]. There is a need to further improve the measurement protocols, and therefore it is important to understand the principles involved in the streaming current method and also to elucidate the role of soluble aluminum compounds as interfering species.

According to St. John [10], aluminum ions "interfere with" titrations involving oppositely-charged polyelectrolytes. In support of this statement, aluminum ions have been shown to affect the endpoints of such titrations that were carried out with either colorimetric [7, 10-13], or streaming current [14] 
detection of the endpoints. In another study, aluminum ions caused a systematic deviation from a roughly linear relationship between streaming current and electrophoretic mobility [15].

In seeking a definition for the word "interfere," it is worth considering the conditions under which accurate and reproducible polyelectrolyte titrations can be expected. These conditions include rapid and complete complexation between the respective polyelectrolytes to result in no residual (uncomplexed) polymer in solution at the equivalence point of the titration. A substance "interferes" in a polyelectrolyte titration if it has the capability to complex with either one of the titrants with sufficient strength as to affect the endpoint. The most troublesome types of interferences would be those that cause deviations that cannot be explained by clear-cut stoichiometric arguments.

Trivalent aluminum can be classified as a hard Lewis acid, having an exceptionally small ionic radius relative to its charge [16]. As such, the aluminum ion has a very strong tendency to complex with such ligands as water, $\mathrm{OH}^{-}$, sulfate, and many other anions that are ubiquitous in industrial applications [16]. In addition, partially hydroxylated aluminum ions have a strong tendency to associate into dimers and certain other multi-aluminum ionic species [3,17-21].

The relative abundance of the different aluminum species in solution has been found to depend on such variables as $\mathrm{pH}$, total aluminum concentration, and time of equilibration. Most notable in this work was the identification of conditions leading to formation of polynuclear ionic species of aluminum [22-25]. The presence of such polynuclear ions was confirmed by colloidal chemical 
analyses, based on the superior coagulating ability of large, multivalent ions [26]. Akitt [22], Crawford [25], and Bottero et al. [23] carried out important work by ${ }^{27} \mathrm{Al}$ nuclear magnetic resonance (NMR) to identify $\left[\mathrm{AlO}_{4} \mathrm{Al}_{12}(\mathrm{OH})_{4}\left(\mathrm{H}_{2} \mathrm{O}\right)_{12}\right]^{7+}$ as the most stable of these polynuclear ions within a $\mathrm{pH}$ range of about $4-5$ at $\mathrm{AlCl}_{3}$ concentrations of $0.1 \mathrm{M}$ or higher. In the literature this species has been called the $\mathrm{Al}_{13}$ ion. In general the proportion of the $\mathrm{Al}_{13}$ ion in a solution tends to increase with hydroxylation up to a ratio of approximately $2.3 \mathrm{OH}$ 's per Al, followed by a sharp decline in favor of $\mathrm{Al}(\mathrm{OH})_{3}$ with further increases in addition of base, relative to the amount of aluminum present. In addition, significant amounts of the ions $\mathrm{Al}(\mathrm{OH})^{2+}$ and $\mathrm{Al}(\mathrm{OH})_{2}{ }^{+}$are known to exist in solution, depending on the $\mathrm{pH}[\mathrm{]}$.

Although one might expect, due to its high valency [26], that trivalent aluminum ions ought to form strong complexes with negatively charged polymers, results of various studies suggest that the impact of the polynuclear ions is much more important [3, 24, 27-30]. For instance, Exall and van Loon [24] found a high correlation between the concentration of $\mathrm{Al}_{13}$ present in solutions and their ability to coagulate raw water samples and remove tannins from the solution phase. In papermaking applications, Strazdins [7] found sharp maxima, as a function of the ratio of added $\mathrm{OH}^{-}$ions to $\mathrm{Al}$, in the ability of aluminum-containing mixtures to complex with an anionic polymer titrant. Also it was found that $\mathrm{pH}$ values corresponding to these maxima tended to decrease with increasing aluminum concentration, a finding that is consistent with 
conditions that would be expected to maximize the proportion of polynuclear ions [7].

Since the present work aims to understand interferences to polyelectrolyte titrations by aluminum ions, it is worth noting factors that affect the proportion of different aluminum species in solution. Crawford [25] was apparently the first to show that the sulfate ion can interfere with the formation of $\mathrm{Al}_{13}$, an effect that is consistent with sulfate's role as a ligand. Such complexation helps to explain, for instance, the fact that aluminum sulfate has a much lower tendency to reverse the zeta potential of negatively charged particles in suspension, compared to solutions of aluminum chloride, after suitable adjustment of $\mathrm{pH}[7,27,29]$. Strazdins [7] and Trksak [8] showed that the coagulating ability of aluminum sulfate or polyaluminum chloride solutions decreased with aging of the solution. Strazdins [31] showed that the "charge decay" of aluminum sulfate solutions was accelerated at high temperature, but that part of the decay could be partially overcome by mixing under conditions of high shear.

To provide focus for the present investigation, two hypotheses are considered, as follows:

First it is proposed that the effects of aluminum ions can be understood as a sum of interactions involving the various aluminum species that are present. Both the colloidal charge and the degree of affinity for the anionic titrant are expected to depend on the aluminum species present during the titration.

The second hypothesis is that aluminum species may deviate strongly from a stoichiometric complexation with polyelectrolytes of opposite charge. 
Such deviations could be attributed to such factors as (a) weaker complexation, (b) slower or interrupted progress towards equilibrium due to the slow dynamics of polymeric rearrangements, (c) a loss of soluble aluminum species in favor of $\mathrm{Al}(\mathrm{OH})_{3}$, and (d) the possible entrapment of positively charged aluminum species within layers of less reactive aluminum hydroxide [7]. A systematic investigation was undertaken to test hypotheses (b) and (c) by looking at the effects of changes in the order of addition for titrations involving aluminum chloride and polyvinyl sulfate (PVSK).

\section{Experimental}

\subsection{Materials}

Similar to the study in the first part of this series [1], the polyelectrolytes used consisted of poly-diallyldimethylammonium chloride (poly-DADMAC), a highly charged poly-base of 400-500 KDalton molecular mass (Aldrich) and polyvinyl sulfate (PVSK), a poly-acid of 170 KDalton molecular mass (Aldrich). Aluminum chloride $\left(\mathrm{AlCl}_{3} \cdot 6 \mathrm{H}_{2} \mathrm{O}\right)$ was purchased from Fisher Chemicals. Ludox® TM-50 colloidal silica of $22 \mathrm{~nm}$ radius (Aldrich) was also used in electrokinetic experiments.

\subsection{Titrations to Evaluate Interference by Al ions}

The titrations were carried out using a PCD $03 \mathrm{pH}$ streaming current instrument (Mütek Analytic). In these experiments two levels of $0.87 \mathrm{mN}$ PVSK solution were added to 1 and $10 \mathrm{mM}$ solutions of aluminum chloride. These initial samples were then titrated with poly-DADMAC $(0.928 \mathrm{mN})$. 


\subsection{Titrations with Adjustment of $\mathrm{pH}$}

The effect of $\mathrm{pH}$ on the titration of aluminum ions with PVSK was investigated by using $\mathrm{pH}$ values of 4.5 and 5 . These $\mathrm{pH}$ levels are common in acidic papermaking systems. Because of limitations inherent to the streaming current device, at least $10 \mathrm{ml}$ volume of aqueous solution was required for reliable results. When PVSK was used as sample, it was first diluted with $15 \mathrm{ml}$ of deionized water (DW). In the case of samples containing aluminum ions, aliquots of $15 \mathrm{ml}$ aluminum chloride solution were added directly without any dilution. In all cases the $\mathrm{pH}$ of the system was adjusted by addition of $0.01 \mathrm{M}$ $\mathrm{NaOH}$ and $0.01 \mathrm{M} \mathrm{HCl}$ solutions.

Experiments were organized into two series according to the way the $\mathrm{pH}$ was adjusted. In the first series the $\mathrm{pH}$ was adjusted during the course of the titrations. In other words, either $\mathrm{HCl}$ or $\mathrm{NaOH}$ as added dropwise, after each 0.1 to $0.3 \mathrm{ml}$ addition of titrant, to keep the $\mathrm{pH}$ as constant as possible. In the second series, the $\mathrm{pH}$ was adjusted before the titrations, allowed to change during the titrations, and then adjusted back to the selected value of $\mathrm{pH}$ at the end of the titrations, if necessary. Additional titrant was added in those cases where adjustment of the $\mathrm{pH}$ caused a change in the streaming current signal (such shifts in signal always required additional titrant to reach an output value of zero). The titrant volume was taken as the sum of all of titrant added until the pH adjustment did not affect the sign of the streaming current.

Additional experiments were carried out in order to examine the charge of the aluminum ions, which could be detected by titration with PVSK over a wider 
range of $\mathrm{pH}$ values. In each experiment $15 \mathrm{ml}$ of $\mathrm{AlCl}_{3}$ solutions of three different concentrations $(0.1,1$ and $5 \mathrm{mM})$ were used as the initial sample, and the $\mathrm{pH}$ was adjusted before and during the titrations. The titrations were carried out using a Mütek PCD-T auto-titrator.

\subsection{Zeta Potential}

Colloidal silica was used as the dispersed phase to make the electrokinetic measurements possible. Aluminum chloride solution concentrations were 0.1 and $1 \mathrm{mM}$. In each experiment $2 \mathrm{ml}$ of $1 \mathrm{wt} \%$ silica was added to $30 \mathrm{ml}$ aluminum chloride solution, which was previously adjusted to the desired pH. A Laser Zee Meter Model 501 was used to measure the electrophoretic mobility of well-mixed dispersions of colloidal silica and the zeta potential was calculated according to the Henry equation [32].

\subsection{Turbidity}

Turbidity tests were carried out with a series of test tubes, with the samples prepared in a manner similar to the zeta potential experiments. After the addition of colloidal silica, the turbidities were measured by means of a DRT15CE Turbidimeter from HF Scientific, Inc. The final concentration of colloidal silica was in each case. After mixing, the measurements were carried out periodically, at specific time intervals, within a period of 24 hours.

\section{Results and Discussion}




\subsection{Aluminum Interference}

Table 1 shows experimental results that support the assertion that aluminum ions can "interfere" with titrations that are carried out between polyelectrolytes of opposite charge [10]. In this discussion, the word "interfere" implies an unpredictable scatter in the data, and that the problem cannot be overcome simply by accounting for the stoichiometry of charged groups on the substance under consideration. In the set of experiments corresponding to Table 1, two different amounts of poly-vinylsulfate (PVSK) were added to two different concentrations of aluminum chloride solution as the samples. The mixtures were then back-titrated with poly-diallyldimethylammonium chloride (poly-DADMAC) to a streaming current endpoint of zero. Results were repeated at two levels of PVSK addition.

\section{[PLACE TABLE 1 NEAR HERE.]}

As shown, addition of the aluminum chloride decreased the amount of poly-DADMAC needed to reach a streaming current output signal of zero. This finding is consistent with an assumption that aluminum species had at least some ability to form a complex with negatively charged groups on the PVSK macromolecules and block the charged sites from access to poly-DADMAC. However, in line with our use of the term "interfere," there was no simple relationship between the amount of aluminum compound added and the degree of shift of the titration between PVSK and poly-DADMAC. Especially troubling, from this perspective, was the fact that in at least one case a higher amount of 
aluminum chloride resulted in less interference with the titration between PVSK and poly-DADMAC.

As a means of defining the efficiency with which soluble aluminum ions form complexes with the anionic polyelectrolyte, calculations first were carried out in terms of the $\mathrm{Al}^{3+}$ ion, neglecting the existence of other stable ionic species. In other words, the titration data were compared to the theoretical efficiencies that one would anticipate based on a model of hexa-hydrated $\mathrm{Al}^{3+}$ ions interacting with the sulfate groups of the PVSK. If such an interaction were to take place with $100 \%$ efficiency, then the expected stoichiometry would be three equivalents of charge of the poly-acid for each one mole of aluminum. However, when this model is applied to the numbers in Table 1, the apparent equivalents of PVSK complexing with each mole of aluminum were scattered between 0.003 and 0.09 . This means that the effect of the aluminum compound was highly inefficient relative to the idealized stoichiometric model based on the unhydrolyzed aqueous aluminum ions. Also, there was no clear pattern in the data. Another possibility is that aluminum ions were in a much lower charged form instead of hexa-hydrated $\mathrm{Al}^{3+}$ ion.

One suspected contributing cause of the non-stoichiometric results in Table 1 was the fact that the $\mathrm{pH}$ was not held constant. Aluminum ionic species are known to depend on $\mathrm{pH}$, which affects their degree of hydrolysis [36-38]. Also, it is to be expected that the complexation interaction between polyDADMAC and PVSK should be much stronger, compared to a competing interaction between aluminum species and PVSK. To address these issues, the 
remaining work was carried out with direct titrations between PVSK and aluminum ion solutions, with the $\mathrm{pH}$ being controlled in different ways. In addition, following the practice introduced in part 1 of this series [1], the order of addition of the interacting compounds also was varied.

\subsection{Direct Titrations at Controlled pH - PVSK First:}

This set of experiments was carried out with PVSK solution initially present in a beaker, adjustment of the $\mathrm{pH}$ to either 4.5 or 5.0 , and then gradual titration with aluminum chloride solution. The $\mathrm{pH}$ was adjusted to its starting value after addition of each aliquot of titrant. These values of $\mathrm{pH}$ were selected for the initial titrations to represent typical "acidic" conditions of paper manufacture [ ]. The initial concentration of PVSK solution was , and aluminum was added in the form of a $\mathrm{mM}$ solution of aluminum chloride.

\section{[PLACE TABLE 2 NEAR HERE.]}

As shown in Table 2, the aluminum compounds acted as a more efficient complexing agent at $\mathrm{pH} 5.0$, compared to 4.5 , for both concentration levels. At $\mathrm{pH} 5.0$ the apparent charge of the aluminum species was 0.5 to 0.65 equivalents per mole of aluminum. By contrast, at $\mathrm{pH} 4.5$ the apparent charge, in terms of the streaming current endpoint, was about 0.25 equivalents per mole of aluminum. Before attempting to interpret these findings it is also worth noting 
that the results depended to a significant extent on the concentration of the titrant (aluminum chloride solution).

To account for the general trend of data in Table 2, calculations were carried out based on a working hypothesis that all of the aluminum was present in the form of the $\left[\mathrm{AlO}_{4} \mathrm{Al}_{12}(\mathrm{OH})_{4}\left(\mathrm{H}_{2} \mathrm{O}\right)_{12}\right]^{7+}\left(\mathrm{Al}_{13}\right)$ ion proposed by others [21]. The ratio of seven charges per 13 aluminum atoms, corresponding to the ion's valence, implies a theoretical charge contribution of 0.538 charge equivalents per mole of aluminum. Though the approximate agreement of this number with the values in Table 2 obtained at $\mathrm{pH}=5$ could be fortuitous, the results are consistent with an efficient, high-affinity interaction mainly between this ionic species and PVSK.

\subsection{Direct Titrations at Controlled $\mathrm{pH}-\mathrm{AlCl}_{3}$ First:}

In the next set of tests to be discussed, the order of addition was reversed. Aluminum solution was placed first in the testing vessel, and the PVSK served as the titrant. Results of preliminary tests showed that even after initial $\mathrm{pH}$ adjustment of the aluminum chloride solutions, subsequent addition of PVSK caused substantial shifts in $\mathrm{pH}$. To overcome such shifts, experiments were repeated under two different methods of $\mathrm{pH}$ control as described in the experimental section. Results are given in Table 3.

[PLACE TABLE 3 NEAR HERE.] 
Results in Table 3 show an apparent conflict. At the higher initial concentration of aluminum chloride solution the most efficient complexing ability, as indicated by the higher values, was obtained at $\mathrm{pH}=4.5$. However at the lower initial concentration of aluminum the highest values of the ratio were obtained at $\mathrm{pH}=5.0$. The values also were different from the results of experiments shown earlier in which PVSK served as the sample.

To interpret the results in Table 3 it is important to note that the relative abundance of aluminum species in solution is expected to be a function of overall aluminum concentration, in addition to $\mathrm{pH}$ [38]. In particular, increasing aluminum concentration is expected to decrease the value of $\mathrm{pH}$ at which the polynuclear aluminum ion species has its greatest relative abundance. Though this circumstance does not prove the mechanism, it is at least consistent with the finding that higher efficiency of the aluminum chloride solution was observed at a higher $\mathrm{pH}$ in the case of the lower initial concentration. It is worth noting that the results for PVSK titrated with $0.001 \mathrm{~mol} / \mathrm{I} \mathrm{AlCl}{ }_{3}$ were fairly close to those for $0.0001 \mathrm{~mol} / \mathrm{I} \mathrm{AlCl} l_{3}$ titrated with PVSK. The calculated final concentrations of $\mathrm{AlCl}_{3}$ after titration in both cases were very close. This finding suggests that the complexation between $\mathrm{PVSK}$ and $\mathrm{AlCl}_{3}$ may be a function of the concentration of $\mathrm{AlCl}_{3}$ in the final solution.

To further test the explanation given above, experiments were carried out over a wider range of $\mathrm{pH}$ and initial concentrations. Due to the relatively good agreement between tests with the two different $\mathrm{pH}$ control methods, all further 
work to be reported was obtained with $\mathrm{pH}$ adjustments being made to the initial solutions and during the course of the titrant additions by the automatic titrator.

\subsection{Apparent Charge as a Function of $\mathrm{pH}$}

To reinforce the findings shown in the previous section, a series of titrations was carried out with aluminum chloride solutions of selected concentrations (see experimental). The $\mathrm{pH}$ was adjusted before the titrations, and then adjusted back to the target value, if necessary, along with the titrant addition. As shown in Fig. 1, the ratio of PVSK to aluminum required to achieve a zero endpoint of the streaming current test depended on $\mathrm{pH}$. At any given value of aluminum concentration in the initial solution, the apparent charge of the aluminum rose to a maximum with increasing $\mathrm{pH}$ and then decreased again. For each aluminum concentration the maximum was achieved at a different $\mathrm{pH}$ value. The higher the aluminum concentration was, the lower the $\mathrm{pH}$ at which the aluminum achieved its maximum ability to complex with PVSK. Notably, under the conditions of testing there was essentially no apparent ability to complex with the PVSK titrant when the $\mathrm{pH}$ of the aluminum-containing solution was either below 3.5 or above 8 .

At each of the three concentrations of aluminum considered, the effective charge approached a maximum of about 0.5 equivalents per mole of aluminum $(\mathrm{OH} / \mathrm{Al}=0.52,0.53,0.52$ with aluminum concentration $1.01,0.507$, and 0.101 $\mathrm{mM}$ respectively). This value is reasonably close to the theoretical value 0.538 for the polynuclear ion $\left[\mathrm{AlO}_{4} \mathrm{Al}{ }_{12}(\mathrm{OH})_{4}\left(\mathrm{H}_{2} \mathrm{O}\right)_{12}\right]^{7+}$, as noted earlier. 


\section{[PLACE FIGURE 1 NEAR HERE]}

One way to interpret the results in Fig. 1 is to propose that the $\mathrm{Al}_{13}$ ion is the only ionic species capable of forming a complex with PVSK. If this hypothesis is true, then the maximum efficiency of the titration ought to correspond, at least approximately, to a fixed ratio of $\mathrm{OH}$ to $\mathrm{Al}$, consistent with the presence of this ion. To test this hypothesis, the results were recalculated and replotted, as shown in Fig. 2.

\section{[PLACE FIGURE 2 NEAR HERE]}

In Fig. 2 most of the data points converge as a single curve. Deviations at the lowest concentration of aluminum tested are tentatively attributed to the expected drift of the streaming current signal that is observed when an aqueous sample contains a very low value of charged colloidal material. Negative values on the plot correspond to cases in which acid, rather than base, had to be added to the aqueous system to achieve a certain target $\mathrm{pH}$. The three curves corresponding to different aluminum concentrations are fairly close in the range of $\mathrm{OH} / \mathrm{Al}$ from 0 to 3 . Aluminum ions reach the maximum complex ability with PVSK at similar ratio of $\mathrm{OH}$ to $\mathrm{Al}$ (degree of neutralization), which is about 1. These results are similar to Reynolds' study that was related to dry strength resins used with alum [33]. The peak areas of the curves are relatively broad in Fig 2, compared with those in Fig 1 when they are plotted against $\mathrm{pH}$. This is to 
be expected, since aluminum solution itself is a good $\mathrm{pH}$ buffer. Figure 3 shows the consumption of base vs. pH.

\section{[PLACE FIGURE 3 NEAR HERE]}

\subsection{Zeta Potential Results}

Because the explanation given in the previous section assumed the existence of the $\mathrm{Al}_{13}$ ion in solution within a certain concentration range, further tests were carried out to test this assumption. Accurate analysis of aluminum species usually requires higher solution concentrations that those used in the present work [22-25]. Therefore, colloidal chemical tests were carried out to obtain further evidence of the existence of polynuclear aluminum species within the range of conditions employed in the streaming current titration experiments.

Figure 4 shows results of tests with $1.00 \mathrm{mM}$ aluminum chloride solutions, to which different amounts of $\mathrm{NaOH}$ had been added to adjust $\mathrm{pH}$. The concentration of aluminum ions was sufficient to cause charge reversal between $\mathrm{pH} 3.5$ and 5 . It is worth noting that the zeta potential became increasingly positive as the $\mathrm{pH}$ was increased between 4 and 5 . In this respect our results are consistent with those of Brace and Matijević [34], who observed positive zeta potentials at similar $\mathrm{pH}$ values during work with somewhat more concentrated solutions $\left(3 \mathrm{mM} \mathrm{Al}\left(\mathrm{NO}_{3}\right)_{3}\right)$. Both sets of results are consistent with the higher expected adsorption tendency of the $\mathrm{Al}_{13}$ ion, compared to hydrated $\mathrm{Al}^{3+}$. There appears to be a consensus in the literature that the latter species is the dominant 
ionic form of aluminum below a pH of about $4[24,28]$, where Fig. 4 shows a lesser positive zeta potential.

\section{[PLACE FIGURE 4 NEAR HERE]}

\subsection{Turbidimetric Tests}

To further confirm the presence of polynuclear aluminum species under some of the aqueous conditions used in this study, Table 4 shows the results of turbidity measurements. In each case $1 \mathrm{mM}$ aluminum chloride was used as the coagulant. For sake of comparison, the measured turbidity of an untreated, stable suspension of the colloidal silica at the same solids level was 3.1 NTU. As shown in the table, the turbidity of the aluminum-treated suspensions was strongly dependent on the added amount of $\mathrm{NaOH}$, or equivalently, on the $\mathrm{pH}$.

At $\mathrm{pH}$ values of 4.25 and 4.49 the suspension not only reached a high initial value of turbidity after mixing, but also the turbidity remained high after 24 hours. It is worth noting that the measured zeta potentials were strongly positive for these two samples, consistent with charge-stabilization of any agglomerates formed during the initial mixing or of any individually dispersed particles. By contrast, unstable suspensions were obtained at $\mathrm{OH}^{-}$addition levels both lower and higher than these two samples. The colloidal instability is particularly evident in those samples in which the turbidity after 24 hours fell to very low levels, consistent with the precipitation of agglomerated material. The results shown in Table 4 are generally consistent with studies by Matijević et al. [35] and by Rubin 
and Hayden [17], in which polynuclear species were proposed to explain results of nephelometric studies with $1 \mathrm{mM}$ aluminum nitrate solutions.

\section{[PLACE TABLE 4 NEAR HERE.]}

Table 5 shows results of tests involving $0.1 \mathrm{mM} \mathrm{AlCl}_{3}$ solutions, which is about a factor of ten less concentrated than was considered in the cited previous work [24]. As shown, the lower concentration conditions yielded results that were very different from those shown in the previous table. Most notably, there was no region of strong charge reversal leading to colloidal stability of the initially-formed agglomerates of particles. Rather, coagulation was maximized at those levels of $\mathrm{OH}^{-}$addition $(4<\mathrm{pH}<5)$ where it would be reasonable to expect the presence of polynuclear aluminum species. Outside of this range the soluble aluminum species had less impact on the original strongly negative zeta potential and high colloidal stability of the dispersions. In summary, at this lower concentration of aluminum ions, the results were consistent with the presence of polynuclear species at $\mathrm{pH}$ values of 4.08 and 4.58 . The results suggest that these ions were almost sufficient to neutralize the surface charge of the solid phase, as evidenced by the initial rise in turbidity, plus the very low values after 24 hours. There was no region of strong charge reversal leading to colloidal stability of the initially-formed agglomerates of particles. Rather, coagulation was maximized at those levels of $\mathrm{OH}^{-}$addition $(4<\mathrm{pH}<5)$ where it would be reasonable to expect the presence of polynuclear aluminum species.

[PLACE TABLE 5 NEAR HERE.] 


\section{Conclusions}

1) Aluminum ions interfered with the stoichiometry of titrations between poly(diallyldimethylammonium chloride) (poly-DADMAC) and potassium poly(vinyl sulfate) (PVSK), even when their concentration was very low compared to the concentration of other inorganic ions present during related experiments described earlier [1, 39].

2) Titrations between PVSK and aluminum ions failed to show a consistent stoichiometry of interaction when the titration was varied, even when the $\mathrm{pH}$ was held constant during the titrations. In other words, different results were obtained, depending on whether PVSK or aluminum ions were used as the titrant or the sample. . When the concentrations of aluminum ions were similar, the stoichiometry was fairly close in both directions.

3) It was possible to titrate the apparent charges of aluminum ions with PVSK under specified conditions of $\mathrm{pH}$. However, the stoichiometry depended on $\mathrm{pH}$ and degree of charge neutralization of aluminum ions.

4) The highest titratable charge occurred within the range of 0.5 to 2 of the $\mathrm{OH} / \mathrm{Al}$ ratio. The highest titratable charge was about 0.5 , when expressed as the ratio of the negative charge-equivalent end point vs. the total moles of aluminum in the solution. This value was consistent with the action of the polynuclear species $\left[\mathrm{AlO}_{4} \mathrm{Al}_{12}(\mathrm{OH})_{4}\left(\mathrm{H}_{2} \mathrm{O}\right)_{12}\right]^{7+}$. 
5) The zeta potential and turbidity results indicated the presence of aluminum polynuclear species, possibly $\left[\mathrm{AlO}_{4} \mathrm{Al}_{12}(\mathrm{OH})_{24}\left(\mathrm{H}_{2} \mathrm{O}\right)_{12}\right]^{7+}$ in the $\mathrm{pH}$ range of 4 to 5. However, current results could not completely explain the interference effect of aluminum ions on the titration stoichiometry between poly-DADMAC and PVSK, and more study would be needed to reach a quantitative understand this effect.

\section{Acknowledgements}

The authors gratefully acknowledge the support of start-up funds from North Carolina State University and the people of North Carolina for the reported work.

\section{References}

[1] J. Chen, J. A., Heitmann, and M. A., Hubbe, Dependency of polyelectrolyte complex stoichiometry on the order of addition. 1. Effect of salt concentration during streaming current titrations with strong poly-acid and poly-base, Colloids Surf. A. 223 (2003) 215-230.

[2] Y. H. Shen, Treatment of low-turbidity water by sweep coagulation using clay, Separation Science and Technology 37 (2002) 2739-2744.

[3] J. Q. Jiang, and N. J. D. Graham, Pre-polymerized inorganic coagulants used for water and waste water treatment, Chem. Ind. 10 (1997) 389-391.

[4] J. Y. Bottero, J. E. Porier, and F. Fiessinger, F., Study of partially neutralized aqueous aluminum chloride solutions: Identification of aluminum species and relation between the composition of the solutions and their efficiency as a coagulant," Progress in Water Techology 13 (1980) 601-612.

[5] J. Y. Bottero, and F. Fiessinger, F., Aluminum chemistry in aqueous solution, Nordic Pulp Paper Res. J. 4 (1989) 81-89.

[6] L. O. Öhman, L. Wågberg, K. Malmgren, and A. Tjernström, Adsorption of aluminum(III) on cellulosic fibers in neutral to alkaline solutions-influence of 
charge and size of the particles formed" J. Pulp Paper Sci. 23 (1997) J467474.

[7] E. Strazdins, The chemistry of alum in papermaking, Tappi J. 69 (4) (1986) 111-114.

[8] R. M. Trksak, Aluminum compounds as cationic donors in alkaline papermaking systems, Proc. TAPPI Papermakers Conf. (1990) 229-237.

[9] S. K. Dentel, and K. M. Kingery, Using streaming current detectors in water treatment, J. Am. Water Works Assoc. 81 (3) (1989) 85-94.

[10] M. R. St. John, and T. M. Gallagher, Evaluation of the charge state of papermachine systems using the charge titration method, Proc. TAPPI 1992 Papermakers Conf,, Nashville, TN, April 5-8, 1992, pp 479-502.

[11] S. Susumu, and Y. Tanaka, Applying colloid titration techniques to coagulant dosage control, Water Sewage Works 113 (1966) 348-357.

[12] R. M. Trksak, Aluminum compounds as cationic donors in alkaline papermaking systems, Proc. TAPPI Papermakers Conf. (1990) 229-237.

[13] M. A. Hubbe, A modified reporting procedure for polyelectrolyte titrations, Tappi J. 62 (8) (1979) 120-121.

[14] T. Kitaoka, and H. Tanaka, Two-dimemsional XPS analysis of aluminum components on the fiber surfaces related to their charge properties at the wet-end, Proc. Int. Symp.Environ. Friendly and Emerging Technologies for a Sustainable Pulp and Paper Ind., Taipei, April 25-27, 2000, 86-90.

[15] S. K. Dentel, A. V. Thomas, and K. M. Kingery, Evaluation of the streaming current detector - 1. Use in jar tests, Water Res. 3 (1989) 413-421.

[16] J. E. Huheey, Inorganic Chemistry: Principles of Structure and Reactivity, Harper \& Row, Publishers, New York, 1972.

[17] P. L. Hayden, and A. J. Rubin, Systematic investigation of the hydrolysis and precipitation of aluminum(III), in Aqueous-environmental chemistry of metals, Rubin, A.J., Ed., Ann Arbor Science. Ann Arbor, MI, 1976

[18] C. Broseet, On the reactions of the aluminum ion with water, Acta Chem. Scan., 6 (1952) 910- .

[19] R. W. Smith, Relations among equilibrium and nonequilibrium aqueous species of aluminum hydroxy complex, Adv. Chem. Ser. 106 (1971) 250279. 
[20] G. Jander, and A. Winkel, Diffusion coefficients of basic aluminum solutions, Z. Anorgan. Allg. Chem. 200 (1931) 257.

[21] G. Johansson, On the crystal structures of some basic aluminium salts, Acta Chem. Scan. 14 (1960) 771-773.

[22] J. W. Akitt, B. L. Khandelw, and N. N. Greenwood, Aluminum-27 nuclear magnetic-resonance studies of sulfato-complexes of hexa-aquo aluminum ion," J. Chem. Soc. Dalton Trans. (1972) 1226-1229.

[23] J. Y. Bottero, J. M. Cases, F. Fiessinger, and J. E. Poirier, Studies of hydrolyzed aluminum chloride solutions. 1. Nature of aluminum species and composition of aqueous solutions, J. Phys. Chem. 84 (1980) 2933-2939.

[24] K. N. Exall, and G. W. van Loon, Effects of raw water conditions on solutionstate aluminum speciation during coagulant dilution, Water Res. 37 (2003) 3341-3350.

[25] R. A. Crawford, and T. A. Flood, Preliminary NMR study on structure of polyaluminum chloride, Proc. TAPPI 1989 Papermakers Conf. (1989) 55-59.

[26] J.-Q. Jiang, and N. J. D. Graham, Pre-polymerized inorganic coagulants and phosphorous removal by coagulation - a review, Water S. A. 24 (1998) 237-244.

[27] E. Matijević, and L. J. Stryker, Coagulation and reversal of charge of lyophobic colliods by hydrolyzed metal lons III aluminum sulfate," J. Colloid Interface Sci. 22 (1966) 68-77.

[28] J. Y. Bottero, J. E. Porier, and F. Fiessinger, Study of partially neutralized aqueous aluminum chloride solutions: Identification of aluminum species and relation between the composition of the solutions and their efficiency as a coagulant, Prog. Water Technol. 13 (1980) 601-612.

[29] T. R. Arnson, and R. A. Stratton, R. A., The adsorption of complex aluminum species by cellulosic fibers, Tappi Journal 66 (12) (1983) 72-75.

[30] J. E. Rodriguez, Uses of aluminum hydroxychloride in the paper industry, Proc. TAPPI Papermakers Conf. (1991) 5-8.

[31] E. Strazdins, Theoretical and practical aspects of alum use in papermaking, Nordic Pulp Paper Res. J. 4 (1989) 128-134.

[32] P. C. Hiemenz, Principles of Colloid and Surface Chemistry, Marcel Dekker, Inc., New York, 1977. 
[33] W. F. Reynolds, Some recent research on Accostrength resin, Tappi J. 44 (2) (1961) 177A-179A.

[34] R. Brace, and E. Matijević, Aluminum hydrous oxide sols - I. Spherical particles of narrow size distribution, J. Inorg. Nucl. Chem., 35 (1973) 36913705 (1973)

[35] E. Matijević, K. G. Mathai, R. H. Ottewill, and M. Kerker, Detection of metal ion hydrolysis by coagulation. III aluminum" J. Phys. Chem. 65 (1961) 826830.

[36] V. A. Nazarenko, and E. M. Newskaya, Spectrophotometric determination of the constants of mononuclear hydrolysis of aluminum ions, Russ. J. Inorg. Chem. 14 (1969) 1696-1699.

[37] P. M. Bertsch, P. M., Aqueous polynuclear aluminum species, in G. Sposito (Ed.) The Environmental Chemistry of Aluminum, CRC Press, Inc., Boca Raton, Florida, 1996.

[38] T. R. Arnson, The chemistry of aluminum salts in papermaking, Tappi J. 65 (3) (1982) 125-130.

[39] J. Chen, M. A. Hubbe, and J. A. Heitmann, Measurement of colloidal charge in the paper mill by streaming current, Proc. TAPPI Papermakers conf., March 2001, CD doc. 


\section{TABLES}

Table 1: Effect of aluminum chloride on the amount of poly-DADMAC required to titrate PVSK solution to a streaming current endpoint of zero

\begin{tabular}{|l|c|c|c|}
\hline${\text { Amount of } \mathrm{AlCl}_{3}}$ & None & $1.01 \times 10^{-3} \mathrm{M}$ & $1.01 \times 10^{-2} \mathrm{M}$ \\
\hline $\begin{array}{l}\text { Poly-DADMAC at endpoint } \\
(\mu \mathrm{eq}),(0.87 \mu \mathrm{eq} \text { of PVSK) }\end{array}$ & $0.87 \pm 0.01^{*}$ & $0.19 \pm 0.05^{*}$ & $0.37 \pm 0.18^{*}$ \\
\hline $\begin{array}{l}\text { Poly-DADMAC at endpoint } \\
(\mu \mathrm{eq}),(1.71 \mu \mathrm{eq} \text { of PVSK) }\end{array}$ & $1.71 \pm 0.01^{*}$ & $0.40 \pm 0.03^{*}$ & $0.43 \pm 0.08^{*}$ \\
\hline pH during titration & & & \\
\hline \multicolumn{2}{|l|}{ Notes: ${ }^{*}=95 \%$ confidence intervals of the measurement results } \\
\hline
\end{tabular}

Table 2: Ratio of PVSK negative groups per aluminum atom at the streaming current endpoint in titrations with $\mathrm{AlCl}_{3}$ as titrant of PVSK solutions

\begin{tabular}{|c|c|c|}
\hline \multirow[t]{2}{*}{ Conditions } & \multicolumn{2}{|c|}{$\begin{array}{l}\text { Aluminum concentration before } \\
\text { addition (moles/liter) }\end{array}$} \\
\hline & 0.001 & 0.0001 \\
\hline $\begin{array}{l}\text { Ratio of PVSK equivalents per mole of Al } \\
\text { at } \mathrm{pH} 4.5\end{array}$ & $0.27 \pm 0.16$ * & $<0.25^{* *}$ \\
\hline $\begin{array}{l}\text { Ratio of PVSK equivalents per mole of Al } \\
\text { at pH } 5.0\end{array}$ & $0.64 \pm 0.05$ * & $0.50 \pm 0.03$ * \\
\hline \multicolumn{3}{|c|}{$\begin{aligned} \text { Notes: }{ }^{*}= & 95 \% \text { confidence intervals of the measurement results } \\
{ }^{* *}= & \text { Overflow of the sample reservoir in the streaming current device } \\
& \text { precluded continuation of experiment beyond this point at } \\
& \text { the higher dilution. }\end{aligned}$} \\
\hline
\end{tabular}


Table 3: Ratio of PVSK negative groups per aluminum atom at the streaming current endpoint when adding PVSK to aluminum chloride solutions, comparing two methods for $\mathrm{pH}$ control

\begin{tabular}{|l|c|c|c|}
\hline \multirow{2}{*}{$\begin{array}{l}\text { Method of } \mathrm{pH} \\
\text { control }\end{array}$} & $\mathrm{pH}$ & \multicolumn{2}{|c|}{$\begin{array}{r}\text { Aluminum concentration in initial } \\
\text { solution (moles/liter) }\end{array}$} \\
\cline { 3 - 4 } & & 0.001 & 0.0001 \\
\hline After each aliquot & 4.5 & $0.56 \pm 0.04 *$ & $0.10 \pm 0.06$ * \\
\hline Simultaneous & 4.5 & $0.48 \pm 0.03^{*}$ & $0.21 \pm 0.05^{*}$ \\
\hline After each aliquot & 5.0 & $0.27 \pm 0.01 *$ & $0.48 \pm 0.01$ * \\
\hline Simultaneous & 5.0 & $0.26 \pm 0.01 *$ & $0.48 \pm 0.01$ * \\
\hline Notes: * $=95 \%$ confidence intervals of the measurement results \\
\hline
\end{tabular}

Table 4: Turbidity of colloidal silica dispersions after partial neutralization of $1.01 \mathrm{mM} \mathrm{AICl}{ }_{3}$ solutions

\begin{tabular}{|l|c|c|c|c|c|c|c|c|c|c|}
\hline $\begin{array}{l}\mathrm{OH}^{-} \text {added per Al } \\
\mathrm{H}_{3} \mathrm{O}^{+} \text {added / Al }\end{array}$ & $\begin{array}{c}- \\
0.17\end{array}$ & $\begin{array}{c}0.04 \\
-\end{array}$ & $\begin{array}{c}0.79 \\
-\end{array}$ & $\begin{array}{c}1.82 \\
-\end{array}$ & $\begin{array}{c}2.80 \\
-\end{array}$ & $\begin{array}{c}2.92 \\
-\end{array}$ & $\begin{array}{c}2.98 \\
-\end{array}$ & $\begin{array}{c}3.10 \\
-\end{array}$ & $\begin{array}{c}3.53 \\
-\end{array}$ \\
\hline $\mathrm{pH}$ & 3.50 & 4.00 & 4.25 & 4.49 & 5.07 & 5.52 & 6.00 & 7.00 & 8.00 \\
\hline Turbidity (NTU) & \multicolumn{7}{|l|}{$\mid$} \\
\hline Initial & 17.5 & 39.8 & 37.1 & 50.1 & 46.9 & 42.0 & 37.4 & 32.3 & 6.08 \\
\hline Maximum & 64.0 & 60.3 & 40.0 & 50.3 & 61.9 & 48.2 & 43.6 & 37.1 & 6.08 \\
\hline After 24 hours & 2.8 & 2.38 & 40.0 & 49.6 & 0.31 & 44.2 & 36.9 & 24.3 & 4.41 \\
\hline Time/max (min) & 150 & 150 & 150 & 3 & 3 & 60 & 90 & 30 & 1 \\
\hline$\zeta(\mathrm{mV})$ & 9.9 & 12.8 & 22.4 & 36.7 & 41.1 & -23.0 & -33.0 & -52.6 & ---- \\
\hline
\end{tabular}


Table 5: Turbidity of colloidal silica dispersions after partial neutralization of $0.101 \mathrm{mM} \mathrm{AICl}_{3}$ solutions

\begin{tabular}{|l|c|c|c|c|c|c|c|c|c|c|}
\hline $\begin{array}{l}\mathrm{OH}^{-} \text {added per Al } \\
\mathrm{H}_{3} \mathrm{O}^{+} \text {added / Al }\end{array}$ & $\begin{array}{c}- \\
6.50\end{array}$ & $\begin{array}{c}- \\
1.29\end{array}$ & $\begin{array}{c}- \\
0.17\end{array}$ & $\begin{array}{c}0.79 \\
-\end{array}$ & $\begin{array}{c}1.68 \\
-\end{array}$ & $\begin{array}{c}2.84 \\
-\end{array}$ & $\begin{array}{c}3.24 \\
-\end{array}$ & $\begin{array}{c}4.31 \\
-\end{array}$ & $\begin{array}{c}5.50 \\
-\end{array}$ \\
\hline $\mathrm{pH}$ & 3.47 & 4.08 & 4.58 & 4.80 & 4.98 & 5.50 & 5.94 & 6.90 & 7.91 \\
\hline Turbidity (NTU) & \multicolumn{7}{|l|}{} \\
\hline Initial & 2.48 & 22.4 & 54.1 & 55.9 & 33.6 & 2.91 & 2.70 & 2.81 & 2.38 \\
\hline Maximum & 2.48 & 51.8 & 53.9 & 56.0 & 33.6 & 2.93 & 2.78 & 2.81 & 2.38 \\
\hline After 24 hours & 2.29 & 16.3 & 0.51 & 0.67 & 31.8 & 2.85 & 2.65 & 2.63 & 2.34 \\
\hline Time/max (min) & 1 & 180 & 10 & 5 & 1 & 5 & 5 & 1 & 1 \\
\hline$\zeta(\mathrm{mV})$ & -11.3 & -2.0 & -14.3 & -0.8 & -18.6 & ---- & -50.7 & ---- & ---- \\
\hline
\end{tabular}




\section{FIGURE CAPTIONS}

Fig. 1. Equivalents of $\mathrm{PVSK}$ required to titrate $\mathrm{AlCl}_{3}$ solutions to a zero streaming current endpoint as a function of $\mathrm{pH}$. The inset shows the amount of $\mathrm{AlCl}_{3}$ added based on total volume.

Fig. 2. Equivalents of $P V S K$ required to titrate $\mathrm{AlCl}_{3}$ solutions to a zero streaming current endpoint as a function of $\mathrm{OH}$-to-aluminum ratio (degree of hydroxylation)

Fig. 3. The relationship between $\mathrm{pH}$ and degree of neutralization. The horizontal axis indicates the molar amount of either acid or base added, based on the aluminum molar concentration.

Fig. 4. Zeta potential of silica particles in presence of $1 \mathrm{mM} \mathrm{AlCl}_{3}$ solutions to which $\mathrm{NaOH}$ was added to adjust the $\mathrm{pH}$ 


\section{FIGURES}
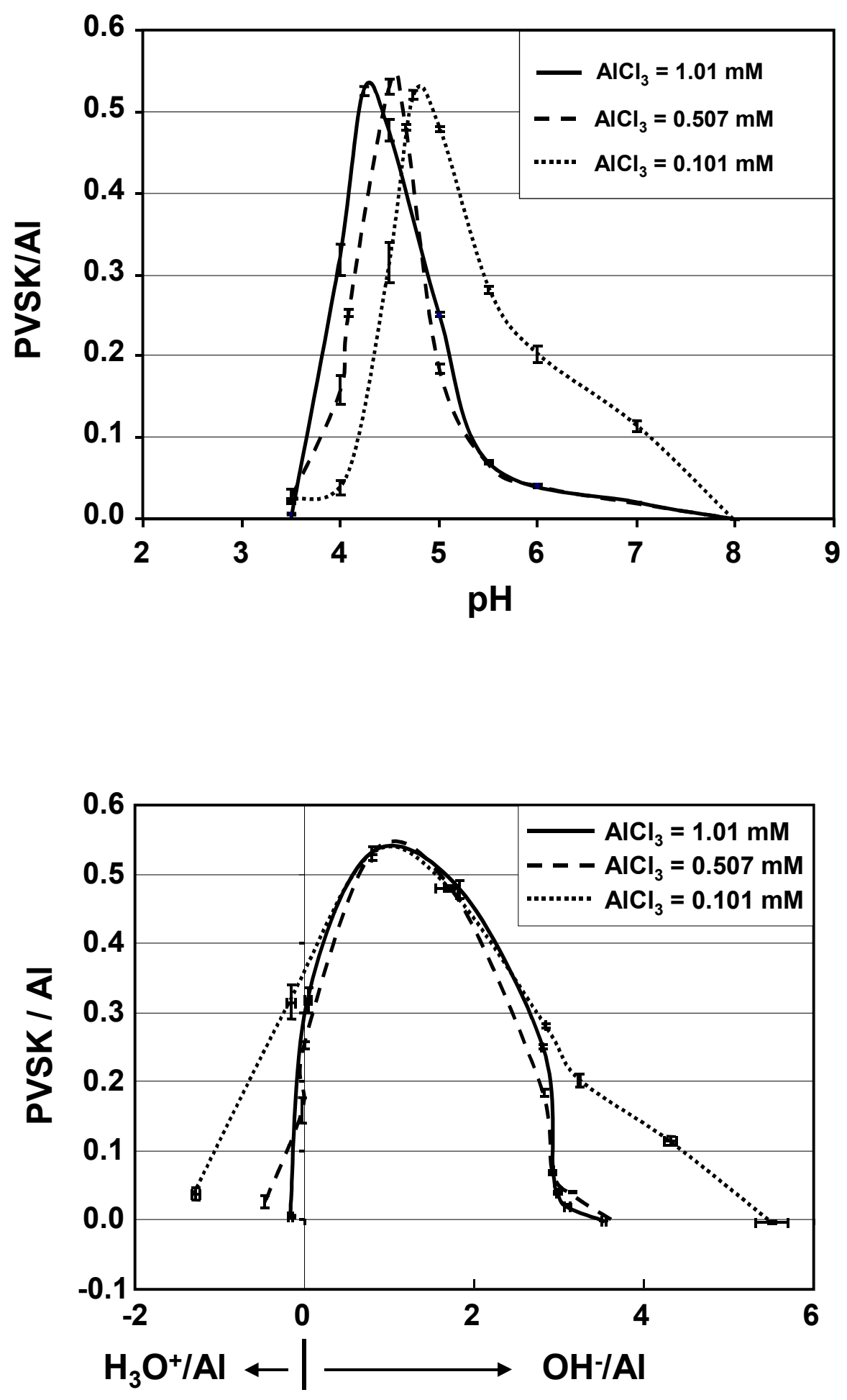

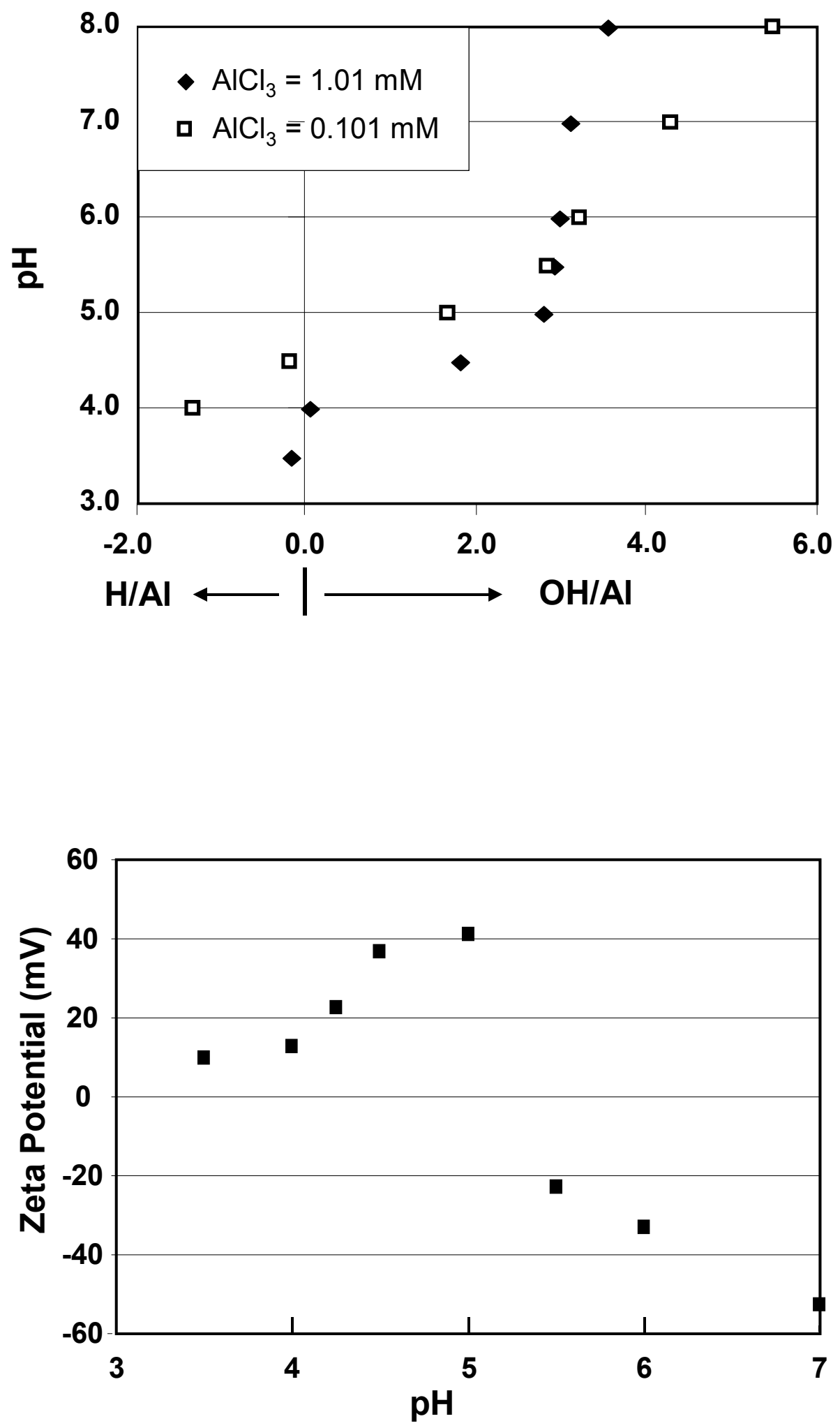